\title{
Higher Education Institution Partnership to Strengthen the Health Care Workforce in Afghanistan
}

Carolyn M. Porta ${ }^{1}$, Erin M. Mann ${ }^{2}$, Rohina Amiri ${ }^{3}$, Melissa D. Avery ${ }^{1}$, Sheba Azim ${ }^{4}$, Janice M. Conway-Klaassen ${ }^{5}$, Parvin Golzareh $^{6}$, Mahdawi Joya ${ }^{7}$, Emil Ivan Mwikarago ${ }^{8}$, Mohammad Bashir Nejabi ${ }^{9}$, Megan Olejniczak ${ }^{10}$, Raghu Radhakrishnan $^{11}$, Olive Tengera ${ }^{12}$, Manuel S. Thomas ${ }^{13}$, Julia L. Weinkauf ${ }^{10}$, Stephen M. Wiesner ${ }^{5}$

${ }^{1}$ School of Nursing, University of Minnesota, Minneapolis, Minnesota, United States of America

${ }^{2}$ Center for Global Health and Social Responsibility, University of Minnesota, Minneapolis, Minnesota, United States of America

${ }^{3}$ University Support in Workforce Development Program, Kabul, Afghanistan

${ }^{4}$ Anesthesiology Department, Kabul University of Medical Sciences, Kabul, Afghanistan

${ }^{5}$ Medical Laboratory Sciences Program, University of Minnesota, Minneapolis, Minnesota, United States of America

${ }^{6}$ Midwifery Department, Kabul University of Medical Sciences, Kabul, Afghanistan

${ }^{7}$ Allied Health Science Department, Medical Lab Technology, Kabul, Afghanistan

${ }^{8}$ National Reference Laboratory, Rwanda Biomedical Center, Kigali, Rwanda

${ }^{9}$ Department of Prosthodontics, Dentistry Faculty, Kabul University of Medical Sciences, Kabul, Afghanistan

${ }^{10}$ Department of Anesthesiology, University of Minnesota Medical School, Minneapolis, Minnesota, United States of America

${ }^{11}$ Office of International Affairs and Collaboration, Manipal Academy of Higher Education, Manipal, Karnataka, India

${ }^{12}$ School of Nursing and Midwifery, University of Rwanda, Kigali, Rwanda

${ }^{13}$ Department of Conservative Dentistry and Endodontics, Manipal College of Dental Sciences, Mangalore, Manipal Academy of Higher Education, Manipal, Karnataka, India

Correspondence: Carolyn M. Porta, School of Nursing, University of Minnesota, Minneapolis, Minnesota, United States of America

Received: November 26, 2019

Accepted: January 6, 2020

Online Published: January 7, 2020

doi:10.5430/ijhe.v9n2p95

URL: https://doi.org/10.5430/ijhe.v9n2p95

\begin{abstract}
Despite ongoing insecurity, Afghanistan has demonstrated improvement in health outcomes. Reasons for this success include a strategic public-private health service delivery model and investment in Afghan health care workforce development. Afghan universities have the primary responsibility for ensuring that an adequate health care workforce is available to private and public health care delivery settings. Most entry-level health care providers working in Afghanistan are educated within the country. However, university constraints, including faculty shortages and limited access to professional development, have affected both the flow of the health care workforce pipeline and the skill levels and competencies of those who do enter the workforce. Aware of these constraints and workforce needs, the administration at Kabul University of Medical Sciences (KUMS), working in collaboration with the Ministry of Higher Education, prioritized investment in strengthening technical and academic capabilities within four faculties (anesthesiology, dentistry, medical laboratory technology, and midwifery). KUMS partnered with the University of Minnesota in 2017 with United States Agency for International Development support through the University Support and Workforce Development Program. Together they established a unique training-of-trainers (TOT) faculty development program to improve faculty knowledge and skills specific to their technical expertise, as well as knowledge and skills in instructional design and research methods. In this article, we describe the successes and challenges associated with partnership development, implementation, and sustainability.
\end{abstract}

Keywords: faculty development, teaching methods, health workforce development, university partnership, training of trainers, health sciences, instructional design, research training 


\section{Introduction}

\subsection{Introduction and Importance of the Problem}

Despite ongoing insecurity, Afghanistan has demonstrated progress in improving health outcomes since 2004 (World Bank Group, 2018) yet continues to lag behind much of the world, as documented in part by persisting unmet sustainable development goals (Sachs, Schmidt-Traub, Kroll, Lafortune, \& Fuller, 2019). Efforts to reach these goals are apparent in the priorities of and investments by the Afghan government in health, social, and economic sectors. With broader societal improvements (e.g. economic development, socio-environmental infrastructures, political stability), there are indirect benefits to population health and well-being. Indeed, life expectancy increases, maternal and child mortality decreases, and the sources of risks to health shift. For example, susceptibility to infectious diseases diminishes while prevalence of non-communicable diseases such as diabetes and heart disease increases. The health care system must evolve to address these changing and increasingly complex health care needs, and the workforce must refine competence and capacity accordingly to ensure a robust and responsive health care system contributes to advancing health in Afghanistan.

Unfortunately, the health care workforce capacity is limited in Afghanistan and unlike nearby countries that can address workforce shortages with immigration and migration of health care workers, Afghanistan is heavily dependent on internal workforce development and capacity building. Internal capacity to address workforce constraints is critical for Afghanistan, a country that is working to re-establish and strengthen an independent governmental structure and one that does not want to become dependent on short-term private or non-governmental organization health care providers to address workforce gaps. Fundamentally, Afghanistan experiences workforce factors similar to those found in many other countries, including (1) the disparities between health care system needs and availability of health care workers in terms of specialty/practice areas and geographical regions, (2) the limited opportunities for the existing health care workforce to receive continuous professional development and remain competitive in providing evidence-based care, and (3) the outpacing of global advances in treatment and technological interventions to existing infrastructure and workforce knowledge and skills.

Additional challenges exist for the universities and institutions of higher education preparing the future health care workforce in Afghanistan. Faculty shortages, challenging student to faculty ratios, limited experiential learning opportunities (e.g., simulation, clinical sites), outdated or unreliable infrastructure and teaching tools, and inadequate curriculum review and revision processes severely constrain the capacity of public higher education. These factors significantly contribute to health care workforce challenges. However, it is at this juncture where there is potential for significant return on investment in terms of sustaining and strengthening a national health care workforce. Certainly, strategic investment in university faculty workforce development has the potential to create a positive waterfall cascade effect upon not only the current and future health care workforce, but ultimately, on the health and well-being of the population and future generations. Partnerships that foster diverse colleague relationship building and delivery of excellent educational preparation and continuous professional development might enable universities to educate a new generation of health care providers and strengthen existing ones. This in turn has potential to drive improvements across the health care system. With nearly all health care workers in every country educated through university and technical institute preparation, it is imperative that university partnerships be established to ensure ongoing review of curricula against international standards and to encourage adoption of best practices in a timely albeit contextualized manner. Historically, despite regional or country-level insecurity anywhere in the world, it is the universities that demonstrate stability and capacity to continue preparing the next generation of professionals. Therefore, there is substantial value to investment in university and faculty development, particularly when a primary goal is strengthening the country-level health care workforce.

\subsection{Literature Review}

Our review of literature since 2010 addressing international partnerships among institutions of higher education demonstrates persistent gaps in knowledge about effective and sustained north-south/east-west/south-south partnerships designed to strengthen and advance higher education institutions in countries such as Afghanistan; this article contributes to addressing this gap.

The available literature can be categorized into three broad areas: (1) literature describing international student learning (Koseva, 2017; Lei, Woodend, Nutter, Ryan, \& Cairns, 2015), student exchanges (Stinson, 2010) and unidirectional service learning opportunities for students coming primarily from high income countries (Reynolds, 2016; Keino, Torrie, Hausafus, \& Trost, 2010); (2) literature describing partnerships aimed at strengthening the capacity of higher education institutions to educate (Taylor, 2016) and to conduct research (Kot, 2014; Semali, Baker, \& Freer, 2013) and (3) literature identifying persisting challenges to international partnerships, including overarching 
logistical challenges (Ayoubi \& Massoud, 2012), power differences (Menashy, Steiner-Khamsi, \& Klees, 2019; Biraimah, 2016; Sharpe \& Dear, 2013), misaligned expectations (Sutrisno \& Pillay, 2015), issues related to "brain drain" of developing countries (Ashton \& Wagman, 2015), and reciprocity efforts to promote equity (Hauerwas \& Creamer, 2018). The second category is most relevant to the partnership described in this article; for example, Sakamoto and Chapman (2012) provide an in-depth examination of the broad ways in which cross-border partnerships can occur and be of value to both institutions of higher education. Siska, van Swet, Pather and Rose (2013) describe how they addressed challenges of institutional partnership across three countries utilizing distinct quality assurance processes and curricular expectations, although all three were in the European Union, which inherently poses different challenges than a north-south partnership. Gieser's (2013) dissertation examined a tri-country university partnership and concluded that one of the most important factors contributing to success were key individuals who operated as champions on their campuses for the partnership; this champion fueling awareness in institutions was similarly found in an evaluation of partnerships among institutions in Tanzania and the Democratic Republic of Congo (Healey, 2018). Mwangi (2017) critiques these partnerships through a lens of mutuality rather than the historic lenses of strategic management and organization theories; doing so offers a candid focus on power differentials that persist in most partnerships even when there is overt effort to equalize the power, priorities, and decision-making among partners. Payumo, Gerard, and Neisler (2019) describe the importance of international partnerships for research advancement and do so whilst recognizing the persisting institutional challenges many faculty experience when they attempt to engage in international collaborative research. This is important because the future of global partnerships among institutions of higher education includes explicit focus on capacity building in research, and not only in educating the next generation workforce (which has been the historic focus of developmental investments in these partnership projects). Finally, our review identified a study demonstrating the value of these partnerships specifically for advancing gender equality and the empowerment of women (Morgan, 2014); our partnership project builds on this dissertation work and explicitly adds to a small literature base establishing the value of these partnerships for women, specifically faculty, in higher education institutions in countries such as Afghanistan.

\subsection{Objective of the Study}

In this article we describe the establishment of a new, multi-national, multi-sectoral partnership to strengthen four faculties at Kabul University of Medical Sciences (KUMS) in Kabul, Afghanistan. The purpose of this article is to describe the successes and challenges associated with our partnership's development, implementation, and sustainability. The article will outline our partnership methods, describe initial results and successes of the program, and discuss challenges and lessons learned. The article will conclude with final reflections on the partnership and a discussion of future research. Successes, challenges, and lessons learned will inform future development of university partnerships aimed at strengthening the health care workforce.

\section{Methods}

\subsection{Partnership Background}

In 2013, the University Support in Workforce Development Program (USWDP) established partnerships among universities in Afghanistan and universities in the United States (US), along with the Afghanistan Ministry of Higher Education. In 2017, KUMS (formerly Kabul Medical University) established a new partnership with the University of Minnesota (UMN) to strengthen four faculties prioritized by the university and government based on current and predicted health care needs across Afghanistan. These include anesthesiology, dentistry, medical laboratory technology, and midwifery (see Table 1 for KUMS faculty and student demographics). With the USWDP funding opportunity ending in 2018, and our sub-award implemented in 2017, our new higher education institution (HEI) partnership was tasked with achieving deliverables within an 18-month timeframe. This narrow timeframe presented challenges that necessitated rapid and strategic multicultural relationship building and knowledge gathering across the HEIs so that we could move ahead with common goals and an agreed upon workplan that would yield overall partnership objectives and provide an initial foundation for long-term sustained relationships. 
Table 1. KUMS faculty and student demographics, by faculty

\begin{tabular}{|c|c|c|c|c|c|c|c|c|}
\hline \multirow{3}{*}{ Faculty } & \multicolumn{6}{|c|}{ Faculty Demographics $^{*}$} & \multicolumn{2}{|c|}{ Incoming Student Class Size } \\
\hline & \multicolumn{3}{|c|}{2017} & \multicolumn{3}{|c|}{2019} & \multirow[t]{2}{*}{2017} & \multirow[t]{2}{*}{2019} \\
\hline & B & M & $\mathrm{P}$ & $\mathrm{B}$ & M & $\mathrm{P}$ & & \\
\hline Anesthesiology & 4 & 1 & 0 & 6 & 2 & 0 & 60 & 60 \\
\hline Dentistry & 15 & 3 & 0 & 16 & 8 & 0 & 172 & 156 \\
\hline Medical Laboratory Technology & 3 & 0 & 0 & 3 & 2 & 0 & 59 & 60 \\
\hline \multirow[t]{2}{*}{ Midwifery } & 0 & 1 & 0 & 1 & 3 & 0 & 58 & 58 \\
\hline & & \multicolumn{5}{|c|}{ *B-Bachelor, M-Masters, P-PhD level education } & & \\
\hline
\end{tabular}

Three core objectives framed this HEI partnership. First, develop advanced clinical knowledge and educational skills of KUMS faculty to educate pre-service health care students (or learners) in coordination with the USWDP and the Ministry of Higher Education. Second, develop advanced pedagogical and leadership competencies of KUMS faculty to implement, evaluate, and continuously revise curricula, in partnership with the Ministry of Higher Education. And third, establish a sustainable partnership model for the HEIs faculty.

In order to achieve these objectives in a relatively short time frame, the following activities were prioritized:

1. Design and implement a faculty training-of-trainers (TOT) model for disseminating current evidence-based practices within each of the four faculties;

2. Revise curricula for the four supported faculties, reflecting international standards and maintaining relevance to the Afghanistan context; and

3. Design and implement a faculty peer-to-peer HEI mentorship program targeting clinical expertise, teaching, and research.

While curricula revisions and the peer-to-peer mentorship were important aspects of the partnership, the focus of this article will be the TOT model.

\subsection{Discipline-Specific Technical Trainings}

The core activity within the training-of-trainers (TOT) model was the development and delivery of specialized, in-person short-course trainings for KUMS faculty with a discipline-specific technical focus. These trainings were held in India, Rwanda, and Egypt and involved significant contributions from UMN-partners in these locations, including Manipal Academy of Higher Education (India), the University of Rwanda, and the National Reference Laboratory in Rwanda. These locations were selected based on the presence of key UMN partners as well as logistical considerations related to travel (e.g. costs of travel involving travelers from both Afghanistan and the US and travel visa considerations). The topics were proposed by KUMS based on self-identified needs and training curriculum was developed by UMN and partners. Training preparations typically involved Skype conference calls with participants to review and agree upon a final agenda, pre-work to be completed by participants, and brief pre-training assessments. Trainings were typically 5 days in length and involved a combination of didactics, hands-on practice, and site visits to classroom or clinical settings. Professional interpreters (Dari-English) were utilized when needed to ensure language was not a significant barrier to learning. A summary of all the trainings is outlined in Table 2.

Table 2. Summary of partnership trainings

\begin{tabular}{llcl}
\hline & Workshop Foci & Instructional Design Strategies & Partners \\
& & &
\end{tabular}


Workshop 1 (Jan/Feb

'18)

Workshop 2 (Apr/May Technical foci:

'18)

\section{Workshop 3}

(Aug '18)

Workshop 4

(Jan '19)

Externship

(Apr '19)

Technical foci: ventilation mapping

\section{Technical foci:} management session) development
Anesthesiology- Shock, transfusion, oxygenation and

Dentistry- Oral surgery and implantology

Medical laboratory technology- Microbiology, student laboratory safety, hematology and curriculum

Midwifery- Physical assessment, physiologic approach to labor and birth and support skills

Anesthesiology- Obstetric Anesthesia

Dentistry- Endodontics and pedagogy

Medical laboratory technology-- microscopy, spectrophotometry, clinical chemistry, PCR, and

ELISA - lab simulations

Midwifery- Newborn and adult resuscitation, obstetric emergencies, specifically postpartum hemorrhage, case study development, visits to clinical sites including a freestanding birth center

Anesthesiology- Regional anesthesia and pain

Dentistry-Orthodontics

Medical laboratory technology-- Cytotechnology and histology; microscopy and special staining; chromatography; arterial and venipuncture techniques - lab simulations

Midwifery- Breast and pelvic examination clinical and teaching skills, analgesia/anesthesia for labor including physiologic support skills (midwifery faculty taught to anesthesia faculty, inter-professional

Instructional design

Research methods and specific research project

Mentorship program progress

Sustainability planning

Four KUMS faculty leaders joined MAHE faculty mentors for two weeks, in clinical observation, teaching, and research activities.

X

$\mathrm{X}$

$\mathrm{X}$

$x$

X $\quad X$

X

X

Manipal Academy

of Higher

Education,

National Reference

Laboratory of

Rwanda,

University of

Rwanda
Manipal Academy of Higher

Education
X Manipal Academy of Higher

Education
X $\quad$ X $\quad$ X
Manipal Academy of Higher

Education 


\subsubsection{Anesthesiology Technical Trainings}

The first anesthesiology technical training covered acute care and critical events, including shock, hypoxia, difficult airway management, rapid sequence induction and Basic Life Support (BLS) / CPR. This training was delivered in Manipal, India and involved collaboration with Manipal Academy of Higher Education. Over the course of several days, content was delivered using mixed methods (e.g. lecture, discussion, problem-based learning discussion) with a heavy focus on hands-on simulation exercises relevant to technical content. Following presentation of the technical material, UMN instructors worked with participants to develop their own short courses appropriate to their home clinical and educational environment. Participants then delivered the courses to each other with feedback and refinement offered by all faculty. The training concluded with a day of clinical observation. The second anesthesiology technical training covered obstetrics, including maternal trauma, pre-eclampsia \& eclampsia, hemorrhage \& transfusion, maternal \& neonatal resuscitation, and interdisciplinary communication and cooperation. This training was delivered in Kigali, Rwanda in collaboration with the University of Rwanda. The training utilized the Safer Anesthesia from Education (SAFE) obstetrics training curriculum - a course developed by the World Federation of the Society of Anesthesiologists (WFSA) and Association of Anesthetists of Great Britain and Ireland (AAGBI). A variety of teaching methods were used / modeled, including lecture, discussion, demonstration, simulation, skill stations, case-based and problem-based discussion. Portions of the SAFE obstetrics course were jointly taught with the midwifery group. In addition to the SAFE obstetric course, participants visited the Kigali University Teaching Hospital to observe their clinical and educational practices. The third anesthesiology technical training provided an introduction to regional anesthesia, including peripheral nerve blocks, local anesthetic toxicity, pain assessment and management. A variety of teaching methods were used / modeled, including interactive lectures, skills stations that integrated flipped classroom, and case study / morbidity \& mortality-style case presentation. Non-traditional teaching modalities were also introduced, including game-style exercises ("Regional Anesthesiology Jeopardy") and responsive classroom techniques. Additionally, one of the sessions was jointly delivered with midwifery faculty and focused on regional anesthesia and physiologic birth techniques.

\subsubsection{Dentistry Technical Trainings}

For all three technical-specific trainings for dentistry, the trainings were conducted in close collaboration with the faculty of Manipal College of Dental Sciences (MCODS), which is affiliated with Manipal Academy of Higher Education. The first dentistry technical training covered basic oral surgery techniques and oral implantology, including dental implant placement, implant impressions, prosthetic considerations, suturing techniques, and platelet-rich fibrin. The objective of this course was to lay a strong foundation in the principle of implantology as well as to update KUMS with the current trends in the field. The course consisted of short lectures and demonstrations. The participants practiced implant placement on dummy models. Additionally, the participants practiced various suturing techniques and witnessed live demonstration of implant placement on a patient. The second dentistry technical training aimed to improve participants' clinical skills in the field of endodontics and to familiarize the participants with the technological advancements in endodontics. Participants were also given hands-on exposure to various contemporary methods used in endodontic practice like the use of surgical microscope, rotary instrumentation, and thermoplastisized obturation technique. The program consisted of short lectures, clinical demonstrations, hands-on workshops, case-based learning and flipped class. Thus, they were acquainted to the flipped classroom model of education where lecture and homework elements of a course are reversed to foster active learning among students (Lin et al., 2017; Park \& Howell, 2015). The dental faculty from KUMS were also familiarized with the concepts and steps in case-based learning. The participants were given a clinical scenario and were asked to explore the problem, identify facts from the scenario, generate hypotheses and discuss the issue with current knowledge (Park \& Howell, 2015; Nadershahi, Bender, Beck, Lyon \& Blaseio, 2013). The learning issues and resources required were discussed. They were then divided into groups and were given access to the resources and were asked to present the case to the rest of the group the following day. The learning outcome were assessed and constructive feedback given. The third technical training of dentistry faculty covered orthodontics, including orthodontic examinations, model/cast analysis, prevention and interceptive orthodontic treatment, and MBT treatment mechanics. Since the program was for a shorter duration in a conference hall rather than a dental clinic, to simulate the clinical setting there were preclinical models and recorded patient videos for the participants to view and discuss. The training involved clinical case discussions, hands-on demonstrations, practical exercises, pre-recorded videos, lectures as well as flipped classroom model of teaching.

\subsubsection{Medical Laboratory Technology Technical Trainings}

The first medical laboratory technology (MLT) technical training focused on microbiology, student laboratory safety, and hematology. The training was held in Kigali, Rwanda and involved collaboration with the National Reference 
Laboratory of Rwanda which is part of Rwanda Biomedical Centre (RBC/NRL) of the Rwanda Ministry of Health. A variety of instructional design techniques were used including a combination of lecture and didactic delivery formats along with hands-on instruction in a laboratory setting. UMN and RBC/NRL faculty demonstrated the use of non-pathogenic organisms to simulate true pathogens in the microbiology training laboratory providing development of essential skills while maintaining a safe learning environment. The training was enhanced by several site visits and tours, including to a referral hospital and clinic laboratory, a rural / low-resource laboratory, and the Rwanda National Reference Laboratory. The second MLT training was also held in Kigali, Rwanda and focused on chemistry, biochemistry, and PCR techniques. This training focused heavily on laboratory-based demonstration and active practice of laboratory techniques using simulated specimens. The final MLT-technical training was held in Bangalore, India and focused on cytology and blood collection. These sessions utilized active learning / hands-on practice with simulation and laboratory equipment to practice skills such as blood collection and preparation and examination of cytology slides. UMN and KUMS faculty worked together to develop laboratory lessons in each discipline that focused on student learning outcomes, testing methods, and diagnostic needs of Afghanistan's medical environment.

\subsubsection{Midwifery Technical Trainings}

The first midwifery technical training focused on health assessment (physical examination techniques) and physiologic support for labor and birth. The training was held in Manipal, India and involved collaboration with Manipal Academy of Higher Education. The training included presentations and group discussions on technical topics with dedicated time for participants to plan a short course on history and physical exam and a short course on physiologic labor support. Participants practiced the techniques with their colleagues in preparation for development of short courses and colleagues provided feedback and suggestions. The second midwifery technical training covered high risk obstetrics, including maternal trauma, pre-eclampsia \& eclampsia, hemorrhage \& transfusion, maternal \& neonatal resuscitation, and interdisciplinary communication and cooperation. SAFE OB topics such as maternal trauma, pregnancy critical care, maternal resuscitation, pre-eclampsia/eclampsia, hemorrhage and other emergencies were taught interprofessionally over 1.5 days by and for midwifery and anesthesiology faculty. This training was delivered in Kigali, Rwanda and involved collaboration with the University of Rwanda (UR) midwifery faculty and included teaching the Helping Babies Breathe curriculum (American Academy of Pediatrics, 2016) as well as postpartum hemorrhage recognition and management. Site visits were arranged by UR faculty to clinical facilities to observe both clinical practice and instructor / student interaction and mentorship. Across these sessions, a variety of teaching methods were utilized / modeled, including lecture, demonstrations, videos, group discussion, clinical observation, and simulation. KUMS participants also spent time developing case studies to be used in new lessons to be taught at KUMS. The third midwifery technical training covered gynecologic examinations. The training featured a review and discussion of pelvic and breast exam techniques using pelvic and breast simulation models followed by practice with the models. Participants presented and discussed ideas for specific simulations and cases to be used during lessons to be added to KUMS midwifery curriculum. A session was also conducted to review and update content and teaching techniques of a mental health course taught at KUMS and attended by midwifery students. Additionally, one of the sessions was jointly delivered with anesthesiology faculty and focused on regional anesthesia and physiologic birth techniques where KUMS midwifery faculty taught techniques learned in the first training.

\subsection{Instructional Design Training}

A wide range of instructional design methods and techniques were presented and modeled during every discipline-specific technical training. These methods and techniques included lecture, demonstration, simulation, flipped classrooms, problem or case-based learning, skills stations, student discussion and brainstorming sessions, "think-pair-share," and alternative teaching techniques (e.g. games) (See Figure 1). During the third in-person training, a multi-day active learning instructional design mini-training was delivered to all four disciplines as a group. The objectives of this mini-training were to (1) strengthen the skills of KUMS faculty to design and redesign lessons based on backward design and active learning principles, (2) design assessments that are aligned to course objectives and (3) integrate active learning strategies within existing courses. The short course was designed so that sections of content were delivered to the large, multi-disciplinary group and then each discipline-specific group practiced and discussed how to integrate the concepts into their curricula. 


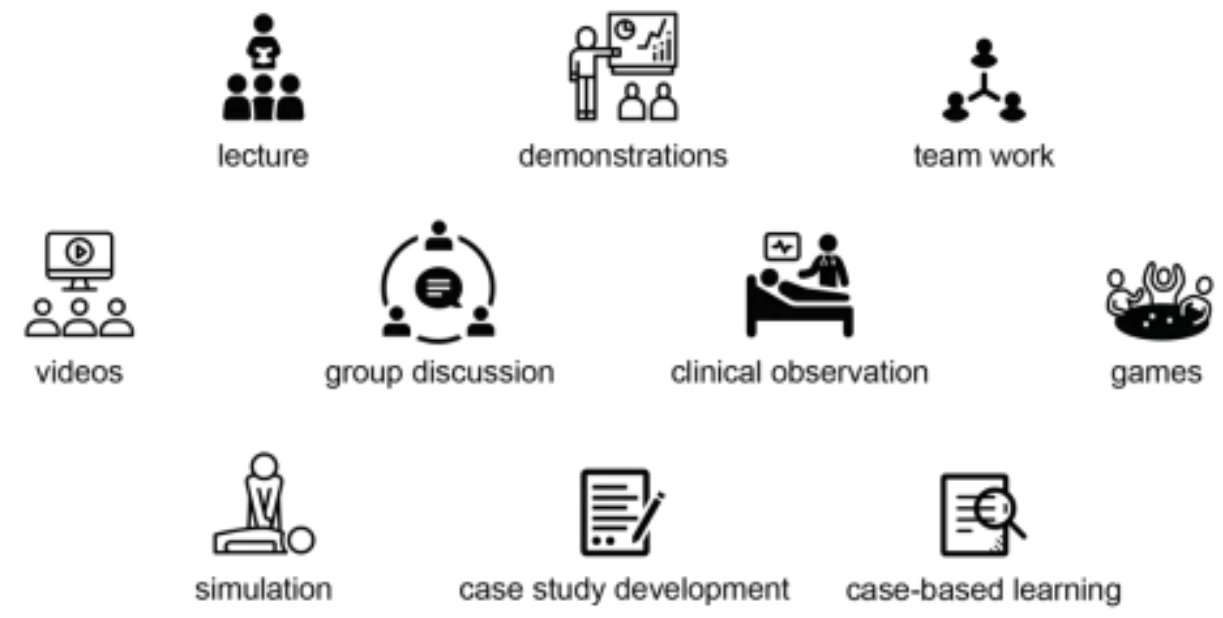

Figure 1. Examples of Teaching Strategies Utilized and Modeled During Partnership Exchanges

\subsection{Research Methods Training}

Research training was identified as a high priority need for KUMS by their faculty and leadership. To address this need, the fourth in-person training was dedicated to advancing knowledge and skills related to research methods. The objectives of this training were to (1) impart knowledge and skills to KUMS faculty to describe common research terms, (2) identify a meaningful research question and basic strategy to answer/test/explore that question, and (3) demonstrate the ability to generate a consistent research question, data source/collection, and analysis plan. Over 4 days, the course faculty delivered a series of foundational presentations that guided participants through various stages of a research project - from development of a research question to selecting a study design to sampling and finally to data preparation and statistical analysis. During small group sessions, KUMS faculty applied new knowledge and skills to their own research ideas. At the conclusion of the training, each discipline presented ideas of possible research projects to the full group. Participants across each discipline expressed that the following points were key take-aways: increased familiarity with statistical software, approaches / databases for conducting a literature review (e.g. PubMed and $\mathrm{MeSH}$ ), development of an appropriate research question, and comparisons of study designs.

\subsection{Interprofessional Education}

Throughout the multiple training sessions, the partnership team worked to integrate interprofessional education. Both the instructional design and research methods short courses were delivered to all four disciplines which fostered discussion and collaboration across the disciplines by virtue of joint participation in the same training. A more focused approach to interprofessional education was taken during portions of the obstetrics-related technical training delivered to anesthesiology and midwifery faculty which was jointly delivered to faculty from both disciplines.

\subsection{Dissemination to KUMS}

The ultimate goal of all in-person trainings was the dissemination of knowledge and skills to KUMS colleagues and students in Kabul. Each training was developed with this goal in mind. Trainings were designed and sufficient resources were provided (e.g. PowerPoint presentations, reference materials, demonstration videos, simulation equipment) so that the faculty could disseminate the information to colleagues in Kabul. During each training program, instructors from UMN and partner organizations balanced teaching new content with demonstrating how to teach the content to colleagues or students. Distance support and feedback was provided in an ongoing manner following each Kabul-based workshop, course, seminar, etc., and to some extent continues at the time of this publication. 


\section{Results and Discussion}

\subsection{Partnership Successes}

The partnership has achieved a number of successes. KUMS faculty across all disciplines have incorporated new interactive instruction techniques, have begun utilizing student-centered approaches, including assessments, and have updated course learning objectives. KUMS anesthesiology faculty are now actively using discussion, think-pair-share, and brainstorming techniques and KUMS dentistry faculty now routinely use problem-based learning, case-based learning, and flipped classroom approaches. The positive impacts of these new approaches have already been observed. In the case of anesthesiology, the reputation of the course has improved as anecdotally reported by the faculty: feedback from KUMS students has been positive, students have been more engaged, and episodes of disruptive students in class have decreased. KUMS midwifery faculty have increased their use of simulation, team work, and case-based and problem-based discussions in their curriculum. These changes have been positively received by students.

Faculty have also incorporated learnings into clinical practice to improve patient care. KUMS anesthesiology faculty have created cognitive aids and an emergency manual for operating theaters, incorporated new techniques into clinical care including Rapid Sequence Induction, and initiated a pain assessment program at the hospital.

Other successes include educational program development. For example, the anesthesiology department established a skills and simulation lab as part of this partnership, the medical laboratory department was equipped with updated tools and instruments for the improvement of student experiences and the midwifery simulation lab was equipped with simulation models and midwifery instructors' offices were equipped with computers and tables. All disciplines underwent curriculum review and revision (pending Ministry of Higher Education approval), with major topics added to each curriculum to make it more consistent with international standards. For example, KUMS midwifery faculty have revised course syllabi and reviewed and updated the general structure of the midwifery curricula as a result of the partnership.

Finally, faculty from KUMS, UMN, and other partner institutions are continuing their collaborations. A number of research collaborations are in various stages, including planning / conceptualization to data collection. For example, anesthesiology faculty are working on research studies related to frequency and predictors of difficult intubation as well as complications of spinal anesthesia.

\subsection{Challenges}

First, the period of performance was relatively short (only 18 months) which only allowed for limited chances for face-to-face meetings / engagement and training opportunities among KUMS faculties and UMN team leads and professors. Second, communication in between face-to-face meetings was limited due to a lack of reliable internet connectivity in Afghanistan. Many resources for teaching and for personal/professional development are openly available on the web but stable, reliable internet access is needed to use these technologies as course resources. Additionally, the lack of reliable internet connectivity also impacted remote engagement. While no large-scale distance trainings were conducted, the UMN/MAHE and KUMS teams corresponded regularly through conference calls. Technical difficulties were frequently encountered while using Skype or similar technologies (Zoom, WebEx) due to connectivity issues. While voice-only calls were typically successful, it was difficult, if not impossible, to reliably do screen / slide sharing.

\subsection{Lessons Learned}

Project successes are directly associated with the quality of the foundational time spent learning about each other-the respective institutions and key partners, identifying the strengths (and weaknesses) each partner institution brings to the partnership/consortium, and clarifying candid partnership goals and expectations. Establishing mutual cross-cultural confidence is critical and requires concrete strategies. First, time to build core relationships of the partnership was essential. New partnerships risk less than optimal success when early stages of the partnership do not build in enough emphasis on relationship-building. Second, being purposeful with and committed to collaborative exercises not only formalized agreed upon work plans, but also fostered cross-cultural understanding and encouraged mutual trust and confidence.

The interprofessional components were very well received, particularly the technical topics jointly delivered to midwifery and anesthesiology faculty. Interprofessional activities could also be explored with other disciplines. For example, medical laboratory technology is used by all of the other disciplines, and future engagement could explore bidirectional education between the laboratory and clinical faculty. Examples of topics include: Nutritional status indicators, diabetes impact on each area of practice, dental infections and treatments; anesthesia and blood 
gases/electrolytes, midwifery and anemia, hemoglobin \& red cell diseases that may impact survival of mother and baby, and maternal/neonatal infections.

UMN and KUMS faculty exchanged ideas related to teaching practices beyond curriculum development. Topics of discussion included classroom management, active learning and flipped classroom delivery formats, faculty time management, and supporting students who struggle. It was very beneficial for the KUMS faculty to learn that UMN faculty have many of the same issues in their classrooms.

\subsection{Sustainability}

As the formal, funded period of the partnership wrapped up in mid-2019, KUMS, UMN, and other partners actively worked to identify strategies to sustain the partnership going forward. First, institutions will work to "formalize" the partnership through mechanisms such as an institutional memorandum of understanding. Second, both primary institutions are actively seeking additional opportunities to formally collaborate, including working on dissemination products. For example, the medical laboratory faculty collaborated across institutions to develop a poster at a national conference in the United States (Wiesner, Conway-Klaassen, Joya, Mwikarago, \& Porta 2018) and midwifery faculty have a poster describing the partnership accepted at the International Confederation of Midwives Triennial Congress in June 2020. Third, strong personal and professional connections have developed between faculty. Through these connections, faculty continue to work together informally on research projects and project dissemination, and to share resources and ideas with each other, including opportunities for KUMS faculty to pursue advanced degrees.

\section{Conclusion}

Institutions of higher education, particularly those that are public with government support, are primarily responsible for preparing the next generation of the workforce, and country leadership and citizens are dependent on these institutions to produce not only high performing professionals but also to advance knowledge, to discover, and to lead innovations in research, practice, and education. This multi-institution, multi-country partnership among universities demonstrated successful relationship-building that yielded significant faculty growth and development in a relatively short period of time. Importantly, this partnership revealed the desire and need for external partnerships that can support Afghan faculty in their pursuit of current best clinical practices, their generation of knowledge that contributes to the health of Afghans, and their commitment to produce competent and confident health care professionals for Afghanistan. Finally, we discovered that much can be accomplished with willingness to build trust, to engage in nontraditional learning strategies, to have fun along the way, and to build relationships and learn from colleagues in different professions, institutions, and countries.

While significant progress has been made in this partnership, there are several opportunities for future work and research. Our Afghan colleagues articulated numerous areas where they hoped to continue building technical knowledge and expertise as well as depth in areas such as conducting research. Efforts in future partnerships should and must continue to respond to Afghan faculty and administration needs in ways that foster mutual relationship outcomes and achieve goals of strengthening the higher education institutions to prepare the future healthcare workforce in Afghanistan. Additionally, there is always value in evaluating the outcomes of partnerships over time, and most projects do not allow for the time or resources needed to do so. Future projects, and partnerships, should build on sustained successes and plan new initiatives with challenges and constraints of the previous partnerships being considered. Finally, these partnerships among institutions of higher education from different countries and regions require time, institutional champions, and ongoing support to yield sustained successes that truly change not only the individuals in the partnerships but the institutions and the target stakeholders-the students, the faculty, the communities in which they will join the healthcare workforce, and the overall country.

\section{Acknowledgements}

The authors acknowledge the faculty and leadership of KUMS for their willingness to trust and partner with new institutions and for their ongoing and long-term commitment to the partnership. The authors acknowledge the faculty colleagues from partner institutions represented in this project who participated in designing and implementing the partnership activities, including Aparna Narayana from Manipal Academy of Higher Education, Anicet Rucogoza from the Rwanda Biomedical Center, and Justine Bagirisano from the University of Rwanda. Sincere thanks as well to Jessamyn Embry and Molly O'Bryan, who provided substantial and critical logistical support for this partnership. There were many others, too many to name, and we are grateful for their engagement and commitment to excellence.

The University of Minnesota partnership with Kabul University of Medical Sciences is made possible by the support of USAID and FHI 360 through award number AID-306-A-13-00009. The contents are the responsibility of the authors and do not necessarily reflect the views of USAID, the US Government, or FHI360. 


\section{References}

American Academy of Pediatrics. (2016). Helping Babies Breathe training program. http://www.aap.org/en-us/advocacy-and-policy/aap-health-initiatives/helping-babies-survive/Pages/Helping-Ba bies-Breathe.aspx

Ashton, W., \& Wagman, L. (2015). Marketing educational improvements via international partnerships under brain drain constraints. Education Economics, 23(6), 713-734. https://doi.org/10.1080/09645292.2014.944100

Ayoubi, R. M., \& Massoud, H. (2012). Is it because of partners or partnerships? An investigation into the main obstacles of developing international partnerships in four UK universities. International Journal of Educational Management, 26(4), 338-353. https://doi.org/10.1108/09513541211227755

Biraimah, K. L. (2016). International Research Partners: The Challenges of Developing an Equitable Partnership between Universities in the Global North and South. Bulgarian Comparative Education Society. https://eric.ed.gov/?id=ED568106

Gieser, J. D. (2013). How multiple actors and contexts influence the implementation of an international academic partnership: A case study [Ed.D., Indiana University]. https://search.proquest.com/docview/1451451887/abstract/2C490E4789B64B0FPQ/1

Hauerwas, L. B., \& Creamer, M. (2018). Engaging with Host Schools to Establish the Reciprocity of an International Teacher Education Partnership. Journal of Higher Education Outreach and Engagement, 22(2), 157-187.

Healey, N. M. (2018). The challenges of managing transnational education partnerships: The views of "home-based" managers vs "in-country" managers. International Journal of Educational Management, 32(2), 241-256. https://doi.org/10.1108/IJEM-04-2017-0085

Keino, L. C., Torrie, M. C., Hausafus, C. O., \& Trost, B. C. (2010). Engaging FCS Partners in an International Service Learning Initiative. Journal of Family and Consumer Sciences, 102(1), 60-62.

Koseva, P. (2017). Internationalizing Campus Partners. Journal of International Students, 7(3), 876-892.

Kot, F. C. (2014). Stakeholder participation in international higher education partnerships: Results of a survey of two sub-Saharan African universities. Tertiary Education and Management, 20(3), 252-272. https://doi.org/10.1080/13583883.2014.936484

Lei, D., Woodend, J. D., Nutter, S. K., Ryan, A. R., \& Cairns, S. L. (2015). The Forgotten Half: Understanding the Unique Needs of International Student Partners. Journal of International Students, 5(4), 447-458.

Lin, Y., Zhu, Y., Chen, C., Wang, W., Liu, Y. (2017). Facing the challenges in ophthalmology clerkship teaching: Is flipped classroom the answer? PloS One, 12(4), e0174829. https://doi.org/10.1371/journal.pone.0174829

Menashy, F., Steiner-Khamsi, G., \& Klees, S. (2019). International Aid to Education: Power Dynamics in an Era of Partnership. Teachers College Press.

Morgan, S. L. C. (2014). The role of an international higher education partnership to improve gender equality and empower women [Ph.D., Biola University]. https://search.proquest.com/docview/1536400487/abstract/7FC6A4AFE1940C2PQ/1

Mwangi, C.A.G. (2017). Partner Positioning: Examining International Higher Education Partnerships through a Mutuality Lens. Review of Higher Education, 41(1), 33-60. https://doi.org/10.1353/rhe.2017.0032

Nadershahi, N. A., Bender, D. J., Beck, L., Lyon, C., \& Blaseio, A. (2013). An overview of case-based and problem-based learning methodologies for dental education. Journal of Dental Education, 77(10), 1300-1305.

Park, S. E., \& Howell, T. H. (2015). Implementation of a Flipped Classroom Educational Model in a Predoctoral Dental Course. Journal of Dental Education, 79(5), 563-570.

Payumo, J., Gerard, A., \& Neisler, G. (2019). Mapping the Benefits of Faculty Development to International Research Partnerships. Journal of Faculty Development, 33(1), 49-63.

Reynolds, N. P. (2016). Is international service-learning win-win?: A case study of an engineering partnership [Ph.D., Temple University]. https://search.proquest.com/docview/1800547684/abstract/80E247D8B3374F41PQ/1

Sachs, J., Schmidt-Traub, G., Kroll, C., Lafortune, G., \& Fuller, G. (2019). Sustainable Development Report 2019. https://www.sustainabledevelopment.report 
Sakamoto, R., \& Chapman, D. (2012). Cross-Border Partnerships in Higher Education: Strategies and Issues. International Studies in Higher Education. Routledge, Taylor \& Francis Group.

Semali, L. M., Baker, R., \& Freer, R. (2013). Multi-Institutional Partnerships for Higher Education in Africa: A Case Study of Assumptions of International Academic Collaboration. International Journal of Higher Education, 2(2), 53-66. http://dx.doi.org/10.5430/ijhe.v2n2p53

Sharpe, E. K., \& Dear, S. (2013). Points of Discomfort: Reflections on Power and Partnerships in International Service-Learning. Michigan Journal of Community Service Learning, 19(2), 49-57.

Siska, J., van Swet, J., Pather, S., \& Rose, D. (2013). From vision to reality: Managing tensions in the development and implementation of an international collaborative partnership programme for institutional change and sustainable development in inclusive education. International Journal of Inclusive Education, 17(4), 336-348. https://doi.org/10.1080/13603116.2011.651825

Stinson, B. L. (2010). International education partnerships: A case study of two universities in the United States and $\begin{array}{lllll}\text { South } & \text { Africa } & \text { [Ph.D., } & \text { New }\end{array}$ https://search.proquest.com/docview/763609055/abstract/22BD60FC35224EF9PQ/1

Sutrisno, A., \& Pillay, H. (2015). Knowledge transfer through a transnational program partnership between Indonesian and Australian universities. Asia Pacific Education Review, 16(3), 379-388. https://doi.org/10.1007/s12564-015-9384-7

Taylor, J. (2016). Understanding International Partnerships: A Theoretical and Practical Approach. Perspectives: Policy and Practice in Higher Education, 20, 44-50. https://doi.org/10.1080/13603108.2015.1062056

Wiesner, S. M., Conway-Klaassen, J., Joya, M., Mwikarago, E. I., \& Porta, C. M. (2019). An International Project for Curriculum and Faculty Professional Development in Medical Laboratory Science. American Society for Clinical Laboratory Science. https://doi.org/10.29074/ascls.119.001396

World Bank Group. (2018). Progress in the Face of Insecurity: Improving Health Outcomes in Afghanistan. https://openknowledge.worldbank.org/handle/10986/29420 